ARAŞTIRMA MAKALESI

\author{
Sübhan Yalcın ${ }^{1}$ \\ Yasin Türker ${ }^{1}$ \\ Hakan Özhan ${ }^{1}$ \\ Yusuf Aslantaş ${ }^{1}$ \\ Yasemin Türker ${ }^{2}$ \\ İsmail Ekinözü ${ }^{1}$ \\ Hakan Tibilli ${ }^{1}$ \\ Ahmet Karabacak $^{1}$
}

${ }^{1}$ Düzce Üniversitesi, Tıp

Fakültesi, Kardiyoloji AD,

Düzce, Türkiye

2 3.No'lu Aile Sağlığ

Merkez, Düzce, Türkiye

Yazışma Adresi:

Dr. Yasin Türker

Düzce Üniversitesi, Tip

Fakültesi, Kardiyoloji AD,

Konuralp, Düzce

Tel:505 6546169

Email:dryasinturker@hotmail.com

Geliş Tarihi: 20.08.2014

Kabul Tarihi: 30.12 .2014

\footnotetext{
Konuralp Tip Dergisi

e-ISSN1309-3878

konuralptipdergi@duzce.edu.tr konuralpgeneltip@gmail.com www.konuralptipdergi.duzce.edu.tr
}

\section{Türk Erişkinlerde Patolojik Ekokardiyografi Bulguları: Epidemiyolojik Gözlemsel Çalışma}

\section{ÖZ}

Amaç: Ekokardiyografi konjenital ve edinsel kalp hastalıklarının tanısında ve izleminde kullanılan, kardiyak yap1 ve işlevlerin değerlendirildiği bir tanı yöntemidir. Günümüze kadar yapılmış, kardiyovasküler hastalıkların ekokardiyografi ile değerlendirildiği birçok çalışma bulunmakla beraber epidemiyolojik araştırmanın yapıldığı geniş ölçekli çalışma sayısı kısıtlıdır. Bu çalışmanın amacı, ekokardiyografi ile saptanabilen kardiyovasküler hastalıkların toplumdaki sıklı̆̆ını araştırmaktır.

Yöntem: Çalışmaya, Düzce ilinin kuzey-doğusundaki Yığılca ilçesinde yaşayan, her aile hekimini temsilen cinsiyet, yaş, kentsel-kırsal dağılım açısından randomize olarak seçilmiş 400 'er kişi (> 17 yaş) davet edildi. Ana çalışma grubunu ortalama yaşı $50 \pm 15$ (18-92 arası) olan 2231 katılımcı oluşturdu. Değerlendirmeler Mayıs-Haziran 2010 tarihlerinde ilçe sosyal sağlık merkezinde yapıldı. Veriler; ölçümler, hastaların özgeçmiş öyküleri ve ekokardiyografi (EKO) aracıllğı ile toplandı.

Bulgular: Ekokardiyografik ölçümler sonucunda, veriler cinsiyete göre değerlendirildiğinde deselerasyon zamanı (DT), Ejeksiyon zamanı (ET) ve pulmoner arter basıncı (PAB) değerleri dışındaki verilerde kadınlarla erkekler arasında ölçümlerde anlamlı fark görüldü $(\mathrm{p}<0,01)$. Diyastolik disfonksiyon (DD) prevalansı \%67,6 saptandı. Veriler cinsiyete göre değerlendirildiğinde, kadınlarla erkekler arasında ölçümlerde anlamlı fark görülmedi $(\mathrm{p}>0,05)$. Çalışma popülasyonunun $\% 3,2$ 'sinde asendan aorta anevrizması saptand. Kalp yetmezliği oranı $\% 1,7$ bulundu. Örneklemin $\% 0,8$ 'inde biküspid aort saptandı. Aort stenozu $\% 3,4$, aort yetmezliği $\% 38,9$, triküspid yetmezliği $\% 52,8$, pulmoner yetmezlik \% 12,4 oranında saptand.

Sonuç: Taşınabilir ve ucuz bir yöntem olması nedeniyle, ekokardiyografinin günümüzde kardiyovasküler hastalıkları değerlendirmede kullanılma oranı artmıştır. Kardiyovasküler hastalıkların erken tanı ve tedavisi ile hastalıkların ilerlemesi engellenebileceği ve hastaların yaşam kalitesinin artırılabileceği göz ardı edilmemelidir. Bu konuda daha fazla bilgi sahibi olmak için gelecekte yapılacak epidemiyolojik çalışmalara ihtiyaç duyulmaktadır.

Anahtar Kelimeler: Epidemiyoloji, Ekokardiyografi, Diyastolik disfonksiyon

\section{Pathologic Echocardiographic Findings among Turkish Adults: an Epidemiologic Observational Study}

\section{ABSTRACT}

Purpose: Echocardiography is used in diagnosis and follow-up of congenital and acquired cardiovascular disease and in assessment of cardiac structure and function. There are many studies that used echocardiography to evaluate cardiovascular diseases but the number of the epidemiological studies is scarce. The aim of this study is to research the frequency of cardiovascular diseases detected by echocardiography.

Methods: The study was conducted in May and June, 2010 in the Social health center located in Yigilca, the north-east of Duzce. 400 adult subjects (>17 years old) from each family physician representatively stratified for sex, age and for rural-urban distribution were randomly assigned and invited to participate the study. A total of 2231 subjects with a mean age of $50 \pm 15$ (age range 18 to 92 ) were interviewed. Data were obtained by measurements and echocardiography.

Results: There was significant difference between men and women in all measurements except deceleration time (DT), Ejection Time (ET) and pulmonary artery pressure PAP values $(p<0.01)$. The prevalence of diastolic dysfunction (DD) was $67.6 \%$. There was no significant difference between men and women $(p>0.05)$. The prevalence of ascending aorta dilatation was $3.2 \%$, heart failure was $1.7 \%$, bicuspid aorta was $0.8 \%$, aortic stenosis was $3.4 \%$. Aortic regurgitation, tricuspid regurgitation and pulmonary regurgitation was detected in $38.9 \%, 52.8 \%, 12.4 \%$.

Conclusion: Because it is a portable and cheap method, the rate of using echocardiography in assessment of cardiovascular diseases increased. It should not ignore that by early detection and treatment, progression of diseases can be prevented and life quality of patients can be improved. Further epidemiological studies are needed to get more information about this issue.

Keywords: Epidemiology, Echocardiography, Diastolic Dysfunction 


\section{GíRiş}

Epidemiyoloji, sağlık ve hastalıkla ilgili olayların dağılımını ve nedenlerini inceleyen, hastalığın kitlesel yönünü çalışan bir bilim dalı olarak tanımlanabilir. Epidemiyolojinin bir bilim olarak tanınması ve sistemli olarak kullanıma girmesi 50 yıldan daha uzun olmayan bir süreçtir. Ancak, kronik hastalıklar başta olmak üzere hastalık sıklığındaki artış, tanı ve tedavi imkânlarındaki yenilikler ve sağlık bakım hizmetlerinin yükselen fiyatları, hastalıkların görülme sıklığı ve başlıca hastalık nedenlerinin doğru tanımlanmasını ve uygun müdahale yöntemlerinin planlanmasını zorunlu kıldığı için, epidemiyoloji bilimi de hızla gelişmiştir (1). Epidemiyolojik çalışmalarla kardiyovasküler risk faktörlerinin incelenmesi, zaman içinde kardiyovasküler hastalıklara yaklaşımda da yeni anlayışlar gelişmesine yol açmıştır.

Günümüzde kardiyoloji alanında kullanılan en değerli noninvaziv tekniklerden biri ekokardiyografidir. Ekokardiyografi konjenital ve edinsel kalp hastalıklarının tanısında ve izleminde kullanılan, kardiyak yapı ve işlevlerin değerlendirildiği bir tanı yöntemidir. S1k ve tekrarlanan incelemelerde bile bilinen herhangi bir yan etkisi olmaması, taşınabilir ve ucuz bir yöntem olması nedeniyle yapılan çalışmalarda $(2,3)$ kardiyovasküler hastalıkları değerlendirmede kullanılma oranı artmıştır.

Ekokardiyografi hareket halindeki

kardiyovasküler sistemin gerçek zamanlı görüntülerini yansıtmak için ultrasonu kullanmaktadır. Ekokardiyografi çesitli görüntüleme ve hemodinamik modalite seçeneği sunmaktadır: 2 boyutlu (2D), M-mod, doppler ekokardiyografi ve renkli akım görüntüleme.

İki boyutlu ekokardiyografi;

ekokardiyografik incelemenin temelini oluşturur. Anatomik yapıların gerçek zamanlı görüntülenmesiyle kapsamlı inceleme sağlanmış olur. Kalp boşluklarının boyutu, duvar kalınlığ global ve bölgesel sistolik fonksiyonu, valvüler ve vasküler yapılar ile ilgili genel bilgiler elde edilebilir. M-mod ekokardiyografi; kalp boşluklarının çapları, duvar kalınlıklarının ölçümü ve özellikle belirli kardiyak yapıların hareket anormalliklerini incelemek için daha sık kullanılır. Doppler ekokardiyografi; sistolik ve diyastolik akım, valvüler lezyonların derecesi, intrakardiyak şantların yeri ve ciddiyeti, diyastolik fonksiyonla ilgili bilgiler sağlayarak M-mod ve 2D ekokardiyografiyi tamamlayıcı özellik göstermektedir (4).

Günümüze kadar yapılmış, kardiyovasküler hastalıkların ekokardiyografi ile değerlendirildiği birçok çalışma bulunmakla beraber epidemiyolojik araştırmanın yapıldığı geniş ölçekli çalışma sayısı kısıtlıdır. Bu çalışmanın amac1, ekokardiyografi ile saptanabilen kardiyovasküler hastalıkların toplumdaki sıklığını araştırmaktır.

\section{GEREÇ VE YÖNTEM \\ Araştırmanın Yapıldığı Toplum ve Seçilen Örneklem \\ $\mathrm{Bu}$ çalışma, Düzce ilinin kuzey-} doğusundaki Yı̆̆ılca ilçesinde yaşayan 2231 kişiyi incelemeye alan ve ekokardiyografi ile saptanabilen kardiyovasküler hastalıkların toplumdaki sıklığını araştırmayı amaçlayan, prospektif şekilde tasarlanmış bir çalışmadır. Değerlendirmeler, Mayıs-Haziran 2010 tarihlerinde ilçe sosyal sağlık merkezinde yapılmıştır. Araştırmanın yapıldı̆̆ coğrafi bölgenin nüfusu 21.000 olup merkezi olan Yığılca ilçesi ve 37 köyü içermektedir. Ekonomik yapısı genelde tarıma dayalıdır. Düzce ilinin ilçeleri arasında sosyoekonomik yönden en az gelişmiş olanıdır ve ilçelerin gelişmişlik sıralamasında Türkiye'deki 872 ilçe içinde 749. sırada yer almaktadır. Ayrıca guatrın endemik olduğu bir bölgedir.

Çalışma Düzce Üniversitesi Tıp Fakültesi tarafından ortak bilimsel araştırma projesi kapsamında gerçekleştirilmiştir. Çalışma protokolü, Düzce Üniversitesi Etik Kurulu tarafindan 12.01.2010 Tarih ve 2010-7 No ile onaylanmış olup katılımcılardan gerekli imzalı onam formları alınmıştır. Veriler; ölçümler, hastaların özgeçmiş öyküleri ve ekokardiografi (EKO) aracılığı ile topland. Bölgenin sağlık hizmeti her biri 2500 yetişkini takip eden 6 aile hekimi tarafından sağlanmaktadır. Çalışmaya her aile hekimini temsilen cinsiyet, yaş, kentsel-kırsal dağılım açısından randomize olarak seçilmiş 400'er kişi (>17 yaş) davet edildi. Ana çalışma grubunu ortalama yaşı 50 (18-92 arası) olan 2231 katılımcı oluşturdu.

Ekokardiyografik ölçümler: Tüm hastalara, doktor tarafindan istirahat halinde, sol dekübit pozisyonunda ekokardiyografik inceleme yapıld1. Parasternal ve apikal pencerelerden gerekli olan iki boyutlu, M-mod, renkli doppler, PW doppler ve TDI doppler görüntüleri $M$ Turbo, SonoSite Inc., Bothell, WA, USA cihazı, 2-5 MHz'lik, alan çalışmaları için spesifik prob kullanılarak alındı ve ölçümler yapıldı. Parasternal kısa ve uzun aks görüntüleri ile apikal dört boşluk ve iki boşluk pozisyonda, iki boyutlu görüntüleme yapıldı (5). Tüm ölçümler en az üç-dört kez tekrar edilip ortalamaları alınd1. Ekokardiyografik ölçümler Amerikan Ekokardiyografi Cemiyeti'nin önerileri doğrultusunda yapıldı (6). Tüm doppler ekokardiyografi ve TDI ekokardiyografi ölçümleri normal respirasyon esnasinda yapıldı.

Bütün katılımcıların standart transtorasik pencerelerden sol ventrikül (LV) ejeksiyon fraksiyonu (EF), diyastol sonu çap1 (LVEDD), sistol sonu çapı (LVESD), interventriküler septum kalınlığ 1 (IVS), posterior duvar kalınlığ 1 (PWT), sol atriyum (LA) ve aort kökü ölçümleri alındı. LV EF 
bi-plane Simpson metodu kullanılarak hesaplandı (7).

Apikal 4 boşluk görüntülerinde $\mathrm{PW}$ Doppler örnek volümü mitral kapak uçları seviyesine yerleştirilerek 5-10 kardiyak atım kaydı alındı. Pik erken (E) ve geç (A) doluş hızları, DT değerleri ölçüldü. CW Doppler ekokardiyografi kullanılarak, CW Doppler “kürsör”"ü LV çıkış yolu akımına paralel olacak şekilde yerleştirildi; IVRT, IVCT ve ET değerleri ölçüldü.

Apikal dört boşluk görüntüsünde, renkli doppler kullanılarak mitral kapak, aort ve triküspit kapak yetersizlikleri değerlendirildi. Sürekli akım (CW) doppler tekniği kullanılarak, pik triküspit yetersizlik (TY) akım hızı elde edildi.

Aort ve mitral kapak seviyelerinde CW doppler ile maksimum ve ortalama gradiyentler hesaplandı. Kesintili akım (PW) doppler ile akımların zaman hız intervali (TVI) ölçüldü.

Araştırmada Kullanılan Tanımlamalar

Hipertansiyon: Kan basınc1 ölçüm ortalamasında sistolik kan basıncının $>140 \mathrm{mmHg}$ ve/veya diyastolik kan basıncının $>90 \mathrm{mmHg}$ olması, hastanın antihipertansif ilaç kullanması veya ilaç kullanımı olmadan hipertansiyon öyküsünün olması hipertansiyon ölçütü olarak kabul edildi.

Asendan aorta dilatasyonu: Asendan aorta çapının $>3,7 \mathrm{~cm}$ olması olarak tanımlandı $(8,9)$.

Normal sistolik fonksiyon: Normal LV sistolik fonksiyonu; normal LV diyastol sonu ve sistol sonu çapları, majör bölgesel kasılma kusurunun olmamas1, EF $\geq \% 50$ olması olarak tanımland1.

Kalp yetmezliği: Bölgesel ya da global kasılma kusurunun olmas1 ve EF $<\% 50$ olmas1 olarak tanımlandi.

Normal diyastolik fonksiyon: Transmitral akımın PW incelemesinde E/A hı oranının > 1 olmas1, DT'nin 160-240 msn arasinda olmasi, IVRT'nin 60-105 msn arasinda olmasi normal diyastolik patern olarak tanımland1.

1. derece diyastolik disfonksiyon: $\mathrm{E} / \mathrm{A}$ oranının $<1$, DT > $240 \mathrm{msn}$ ve IVRT > $90 \mathrm{msn}$ olmasi olarak tanımland1.

2. derece diyastolik disfonksiyon: E/A 1-2, DT 160-240 msn, IVRT $<90 \mathrm{msn}$ ve ön yükü azaltan Valsalva manevrası ile E/A $<1$ olması olarak tanımland1.

3. derece diyastolik disfonksiyon: $\mathrm{E} / \mathrm{A}>2$, DT <160 msn, IVRT < 70 msn ve PVd / PVs > 1,5 olması olarak tanımlandı.

Ileri aort stenozu: Jet hiz1 $>4 \mathrm{~m} / \mathrm{s}$, ortalama gradiyent $>40 \mathrm{mmHg}$ ve kapak alanı $<1$ $\mathrm{cm}^{2}$ olması olarak tanımland.

Ileri aort yetmezliği: Yetmezlik akım genişliği / LVOT çapı oranı >\%65, vena kontrakta $>6 \mathrm{~mm}$ ve PHT $\leq 250$ msn olması olarak tanımland.

Ileri mitral stenozu: Ortalama gradiyent $>10 \mathrm{mmHg}, \mathrm{PAB}>50 \mathrm{mmHg}$ ve kapak alanı $<1,0$ $\mathrm{cm}^{2}$ olması olarak tanımland.
Ileri mitral yetmezlik: $\mathrm{Reg} \mathrm{V} \geq 60 \mathrm{~mL}$, vena kontrakta $\geq 7 \mathrm{~mm}$ ve yetmezlik jet akım/ LA oran1 $>\% 40$ olmasi olarak tanımlandi.

Ileri triküspit stenozu: Ortalama gradiyent $>7 \mathrm{mmHg}$ ve kapak alanı $<1,0 \mathrm{~cm}^{2}$ olması olarak tanımlandi.

İleri triküspit yetmezliği: Vena kontrakta $>7$ mm olması olarak tanımland.

Ileri pulmoner stenoz: Jet akım hiz1 $>4$ $\mathrm{m} / \mathrm{s}$ ve maksimum gradiyent $>60 \mathrm{mmHg}$ olmasi olarak tanımlandi.

Ileri pulmoner yetmezlik: Renkli jet akımın sağ ventrikül çıkış yolunu doldurması ve dik eğim gösteren $\mathrm{CW}$ Doppler sinyali alınması olarak tanımland1.

İstatistiksel analizler:

$\mathrm{Bu}$ çalışmada veriler SPSS (Statistical Package for Social Sciences) for Windows 16.0 istatistik programı ile bilgisayar ortaminda değerlendirildi ve $\mathrm{p}$ anlamlılık seviyesi $<0,05$ olarak kabul edildi. Elde edilen verilere ait tanımlayıc parametreler ortalama \pm standart sapma, sayı ve yüzde $(\%)$ olarak tablo halinde verildi. Gruplar arasındaki ortalama ve oranlardaki farklılıkları analiz etmek için Pearson's chi-square testleri kullanıldı.

\section{BULGULAR}

Çalıșma grubunun özellikleri Tablo 1 'de sunulmuştur. Çalışmaya, ortalama yaşı $50 \pm 15$ olan 2231 katılımcı dahil olmuştur. 1428' i (\%64) kadın, 803'ü (\%36) erkekti. Katılımcıların özgeçmiş öykülerine göre \%29'unun hipertansiyon, $\% 12$ 'sinin diabetes mellitus ve \%6'sinın $\mathrm{KAH}$ tanisi mevcuttu.

Ekokardiyografik ölçümler sonucunda, sol atriyum çap1 $3.41 \pm 0.47 \mathrm{~cm}$ (kadınlarda $3.35 \pm 0.47$, erkeklerde $3.51 \pm 0.46)$, asendan aorta çap1 $3.02 \pm 0.39 \mathrm{~cm}$ (kadınlarda 2.93 \pm 0.35 , erkeklerde $3.17 \pm 0.40)$, interventriküler septum kalınlığ 1 $1.01 \pm 0.18 \mathrm{~cm}$ (kadınlarda $0.99 \pm 0.19$, erkeklerde $1.04 \pm 0.17$ ), posteriyor duvar kalınlığ $0.97 \pm 0.15 \mathrm{~cm}$ (kadinlarda $0.95 \pm 0.16$, erkeklerde $1.01 \pm 0.14$ ), sol ventrikül sistol sonu çap1 $3.02 \pm 0.48 \mathrm{~cm}$ (kadınlarda $2.96 \pm 0.47$, erkeklerde $3.13 \pm 0.49$ ), sol ventrikül diyastol sonu çapı $4.64 \pm 0.53 \mathrm{~cm}$ (kadınlarda $4.55 \pm 0.51$, erkeklerde $4.78 \pm 0.52$ ), EF $\% 63 \pm 5.85$ (kadınlarda 64 \pm 5.0 , erkeklerde $62 \pm 6.9$ ) olarak saptand1. Veriler cinsiyete göre değerlendirildiğinde kadınlarla erkekler arasında ölçümlerde anlamlı fark görüldü $(\mathrm{p}<0,05)$.

E dalgası ortalama değeri $0.73 \pm 0.21$ (kadınlarda 0.75 \pm 0.21 , erkeklerde 0.19), A dalgası ortalama değeri $0.72 \pm 0.19$ (kadınlarda $0.73 \pm 0.20$, erkeklerde $0.69 \pm 0.18$ ), DT ortalama değeri $201 \pm 51.0$ msn (kadınlarda 200 \pm 50.8 , erkeklerde $202 \pm 51.3$ ), IVRT ortalama değeri $107 \pm 37.4 \mathrm{msn}$ (kadınlarda 104 \pm 26.7 , erkeklerde $112 \pm 51.0$ ), IVCT ortalama değeri $57 \pm 26.8 \mathrm{msn}$ (kadınlarda 56 \pm 22.0 , erkeklerde $60 \pm 33.7$ ), ET ortalama değeri $107 \pm 41.8$ msn (kadınlarda 267 \pm 42.2 , erkeklerde 263 \pm 40.8 ), PAB ortalama değeri $22.2 \pm 11.5 \mathrm{mmHg}$ (kadınlarda $22.2 \pm 11.4$, erkeklerde $22.4 \pm 11.7$ ) olarak saptand1. 
Veriler cinsiyete göre değerlendirildiğinde DT, ET ve $P A B$ değerleri dışındaki verilerde kadınlarla erkekler arasında ölçümlerde anlamlı fark görüldü. $(\mathrm{p}<0,05)$.

Çalışma popülasyonunun \%3.2'sinde asendan aorta anevrizması saptand1. Örneklemin $\% 0,8$ 'inde biküspid aort saptand1. Kalp yetmezliği oran1 \% 1.7 bulundu.

Diyastolik disfonksiyon incelendiğinde; örneklemin \%57,3'ünde 1. derece DD, \%10,2'sinde 2. derece DD, \%0,1'inde 3. derece DD olduğu saptandı. \%32,4'ü normal diyastolik fonksiyonlara sahipti. Veriler cinsiyete göre değerlendirildiğinde kadınlarla erkekler arasında ölçümlerde anlamlı fark görülmedi ( $\mathrm{p}>0,05)$.

Aort stenozu \%3,4, aort yetmezliği \%38,9, triküspid yetmezliği \%52,8 (\%1,3 ileri TY), pulmoner yetmezlik \%12,4 oranında saptand.

Tablo 1. Ekokardiyografik ölçümler sonucunda saptanan veriler

\begin{tabular}{lcc}
\hline Değerler & Ortalama & $\begin{array}{c}\text { Standart } \\
\text { sapma }\end{array}$ \\
\hline Sol atriyum (cm) & 3,41 & 0,47 \\
Asendan aorta (cm) & 3,02 & 0,39 \\
İnterventriküler septum (cm) & 1,01 & 0,18 \\
Posteriyor duvar kalınlığı (cm) & 0,97 & 0,15 \\
LV sistol sonu çapı (cm) & 3,02 & 0,48 \\
LV diyastol sonu çapı (cm) & 4,64 &, \\
Ejeksiyon fraksiyonu (\%) & 63 & 5,85 \\
E dalgası & 0,73 & 0,21 \\
A dalgası & 0,72 & 0,19 \\
DT (msn) & 201 & 51,02 \\
IVRT (msn) & 107 & 37,4 \\
IVCT (msn) & 57 & 26,8 \\
ET (msn) & 266 & 41,8 \\
Pulmoner arter basıncı & 22,2 & 11,5 \\
(mmHg) & & \\
\hline
\end{tabular}

\section{TARTIŞMA}

Ekokardiyografi kalp boşlukları ve duvar kalınlıklarının ölçümünde, kapak hastalıklarının değerlendirilmesinde, kalbin anatomik ve işlevsel bozukluklarının tanımlanmasında yaygın olarak kullanılmaktadır. Özellikle son 20 yılda ekokardiyografik tekniklerde önemli gelişmeler olmuştur. Bu sayede iki boyutlu çözünürlük artmış, ölçümlerin daha sağlıklı yapılabilmesi sağlanmıştır.

Ekokardiyografi kullanılarak çeşitli kardiyovasküler hastalıkların prevalansı, prognozu ve tedavi algoritması hakkında birçok çalışma yapılmıştır $(10,11,12)$.

Kalp yetmezliği (KY) ile ilgili yapılmış bir çalışmada (12), Güney Amerika'da 65 yaş üstü olgularda KY prevalansı \%4 olarak saptanmışken, Arap nüfusu üzerinde yapılan bir başka çalışmada (13) prevalans 5.17/1000 olarak saptanmıştır. 1997' de Tarazzi (14), kalp yetmezliği prevalansının 320/1000, 65 yaş üstünde ise 30-100/1000 olduğunu belirtmiştir. Yine 1997'de McDonagh ve arkadaşları, 1640 hasta ile yaptıkları bir çalışmada
(15), çalışma grubunun \%2,9’unda kalp yetmezliği saptadıklarını bildirmişlerdir.

Schocken ve arkadaşları 1992'de (16), Amerika Birleşik Devletleri'nde kalp yetmezliği prevalansını \%1,1 olarak saptamışlarken, Framingham çalışması erkek cinsiyette 24/1000, kadın cinsiyette 25/1000 gibi bir prevalans oranı yansitmıştır (17).

Rotterdam Çalışması'nda (18), 55 yaş ve üstü olgularda kalp yetmezliği prevalansı $\% 3,9$ saptanmıştır. Yine aynı yıl Amerika'da yapılan bir çalışmada (19) saptanan KY prevalansı \%2,2'dir.

Son olarak yakın zamanda ülkemizde yapılmış geniş ölçekli epidemiyolojik bir çalışma olan "Türkiye'deki kalp yetersizliği prevalansı ve öngördürücüleri; HAPPY çalışması” nda (20), KY prevalansı $\% 2,9$ olarak bildirilmiştir.

Yaptığımız çalışmada kalp yetmezliği prevalans $1 \% 1,7$ olarak saptanmıştır.

Günümüze kadar yapılan birçok çalışmada (21-25), kalp yetmezliği nedenli hastaneye yatışların \%30-50'sinde sebebin diyastolik disfonksiyon olduğu bildirilmiştir. Ancak, diyastolik disfonksiyon her zaman semptomatik olmamaktadır. Yapılan çalışmalarda (26-29), genel popülasyonda diyastolik disfonksiyon prevalans1 $\% 11,1$ ile \%34,7 arasında değişmektedir.

Diyastolik disfonksiyon ile ilgili yapılmış bir çalışmada (30), 520 hasta Doppler ekokardiyorafi ile değerlendirilmiş, hastaların 290' unda (\%56) diyastolik disfonksiyon saptanmıştır. Fischer ve arkadaşlarının yaptıkları çalışmada (29), diyastolik disfonksiyon erkeklerde \%13,8, kadınlarda \%8,6 oranında saptanırken, Pedersen ve arkadaşlarının yaptıkları bir çalışmada da (31) benzer oranlar bulunmuştur. Yine bir başka çalışmada (27) 2002-2003 yılları arasında, 60-86 yaş arası 1.275 hasta çalışmaya dahil edilmiştir. Hastalar Doppler ekokardiyografi ile değerlendirilmiş ve diyastolik disfonksiyon prevalansı \%34,7 olarak bildirilmiştir.

Proteger çalışmasında (32) ortalama yaşı 87 olan 331 hastaya ekokardiyografik inceleme yapılmış ve DD prevalansı \%10 oranında bulunmuştur. Mohamed ve arkadaşları, hipertansiyon tanılı 50 hasta ile yaptıkları çalışmada (33), hastalardan 22'sinde (\%44) DD saptandı̆̆ bildirmişlerdir. Adamu ve arkadaşları (34) ise yaptıkları çalışmada yeni hipertansiyon tanısı konmuş 150 hastadan \%62'sinde DD saptamışlardır. Movahed ve arkadaşlarının yaptıkları bir çalışmada (35) DD prevalansı \%36 olarak bildirilmiştir.

Yaptığımız çalışmada DD prevalansı $\% 67,6$ (\%57,3'ünde 1. derece DD, \%10,2'sinde 2. derece DD, \%0,1'inde 3. derece DD) oranında bulunmuştur. Mitral kapak alanı $<1,5 \mathrm{~cm}^{2}$ olan MS'li 119 hastayla yapılmış bir çalışmada (36), KAH \%1,7 oranında saptanmışken, Güray ve arkadaşları (37) mitral kapak alanı $\leq 1,5 \mathrm{~cm}^{2}$ olan MS'lu 837 hastayla yaptıkları çalışmada KAH prevalansını $\% 7,5$ oranında bulmuşlardır. 
Movahed ve arkadaşlarının 2006' da mitral stenoz ile ilgili yaptıkları bir çalışmada (38), toplamda 24.265 hastaya ekokardiyografik inceleme yapılmıştır. 12.926 kadın (\%53), 11.339 erkek (\%47) üzerinde yapılan bu çalışmada, mitral stenoz prevalansı \%2 olarak saptanmıştır (kadınlarda \%1,6, erkeklerde \%0,4). Yine aynı çalışmada, mitral yetmezliği kadınlarda \%24,4, erkeklerde $\% 25$ oranında saptanmıștır.

Diao ve arkadaşlarının (39) kalp hastalığı öyküsü olan gebe kadınlar üzerinde yaptıkları bir çalışmada mitral stenoz $\% 76$ oranında bulunmuştur. Çalışmamızda MS prevalansı \%1,9 bulunmuştur.

$$
\text { Reid ve arkadaşları, CARDIA }
$$
çalışmasında (40), 21-35 yaş arası 4.352 hastaya ekokardiyografik inceleme yapmışlardır. Çalışma sonunda \% 10,4 oranında MY, \%0,8 oranında AY saptamışlardır.

KY'li hastalarda MY'nin araştırıldığ 1 başka bir çalışmada (41), 370 hastaya ekokardiyografik değerlendirme yapılmış, hastalardan 345'inde (\%94) MY saptanmıştır. Strong Heart çalışmasında (10) 3.486 hastaya ekokardiyografi yapılmış ve MY prevalansı \%21,3 bulunmuştur.

Singh ve arkadaşlarının yaptıkları geniş ölçekli bir çalışmada (42), MY, TY ve AY prevalansı araştırılmıștır. 1.696 erkek, 1.893 kadın üzerinde yapılan ekokardiyografik inceleme sonucunda erkeklerde orta-ciddi MY \%19,0, TY $\% 14,8$ saptanırken kadınlarda orta-ciddi MY $\% 19,1$, TY \%18,4 oranında saptanmıştır. Erkeklerde orta-ciddi AY \%13,0, kadınlarda \%8,5 oranında görülmüştür.

Yine başka bir çalışmada (43), MVP tanılı 80 hastada MY prevalansı araştırılmıştır. 55 hastada (\%69) MY saptanmıştır. Çalışmamızda MY prevalans1 \%69,6 (hafif MY \%53,8, orta MY $\% 13,4$, ileri MY \%2,4), AY prevalans1 \%38,9, TY prevalansı \%52,8 (\%1,3 ileri TY) saptanmıştır.

Sonuç olarak, çalışmamız Düzce'de Yığılca bölgesi erişkin nüfusa ait ekokardiyografi ile saptanabilen hastalıkları araştıran geniş ölçekli epidemiyolojik bir çalışmadır. Günümüze kadar yapılmış, kardiyovasküler hastalıkların ekokardiyografi ile değerlendirildiği birçok çalışma yapılmış, ekokardiyografi ile saptanabilen hastalıkların prevalansı araştırılmıştır. Çalışmamızda, yaş ortalaması $50 \pm 15$ olan 2.231 kişiden oluşan homojen bir grupta ekokardiyografi ile saptanabilen hastalıkların prevalansını araştırdık. $\mathrm{Bu}$ çalışma ile asemptomatik hastalarda kalp yetmezliği, diyastolik disfonksiyon tespit edilmiş olup klinik yarar elde edilmiştir.

\section{KAYNAKLAR}

1. Cakir B. Genetik Epidemiyoloji: Psikiyatrik Araştırmalarda Yeri ve Kullanımı Türk Psikiyatri Dergisi 2002; 13(4):300-11.

2. Devereux RB, Liebson PR, Horan MJ. Recommendations concerning use of echocardiography in hypertension and general population research. Hypertension. 1987;9(suppl II):II-97-II-104.

3. Savage DD, Garrison RJ, Kannel WB, et al. Considerations in the use of echocardiography in epidemiology: the Framingham study. Hypertension. 1987;9(suppl II):II-40 -II-44.

4. Gottdiener JS, Bednarz J, Devereux R, et al. American Society of Echocardiography. Report from the American Society of Echocardiography's Guidelines and Standards Committee and The Task Force on Echocardiography in Clinical Trials Journal of the American Society of Echocardiography. J Am Soc Echocardiogr. 2004;17(10):1086-119.

5. Feigenbaum H, Armstrong WF, Ryan T. Echocardiography (7th ed). Philadelphia 2005;105-37.

6. Henry WL, DeMaria A, Gramiak R, et al. Report of the American Society of Echocardiography Committee on Nomenclature and Standards in Two-dimensional Echocardiography. Circulation, 1980;62:212-7.

7. Sahn DJ, De Maris A, Kisslo J, et al. For the committee on M-mode standardization of the American Society of Echocardiography Recommendation regarding quantitation in M-mode echocardiographic measurements. Circulation 1978;58:1072-83.

8. Penn MS, Smedira N, Lytle B, et al. Does coronary angiography before emergency aortic surgery affect inhospital mortality. J Am Coll Cardiol 2000;35:889-94.

9. Papadakis MC, Leontiadis E, Manginas A, et al. Frequency of coronary artery in patients undergoing surgery for ascending aortic aeurysms. Am J Cardiol 2004;94:1433-5.

10. Jones EC, Devereux RB, Roman MJ, et al. Prevalence and corrallates of mitral regurgitation in populationbased sample (The Strong Heart Study). Am J Cardiol 2001;87:298-304.

11. Devereux RB, Jones EC, Roman MJ, et al. Prevalence and correlates of mitral valve prolapse in a population-based sample of American Indians: The Strong Heart Study. American Journal of Medicine, 2001;111:679-85

12. Mendez GF, Cowie MR. The epidemiological features of heart failure in developing countries: a review of the literature. Int J Cardiol 2001;80:213-19.

13. Agarwal AK, Venugopalan P, de Bono D. Prevalence and aetiology of heart failure in an Arab population. Eur J Heart Failure 2001;3:301-5.

14. Tarazzi L. Epidemiology of dilated cardiomyopathy: a still undetermined entity. Eur Heart J 1997;18:4-6. 
15. McDonagh TA, Morrison CE, Lawrence A, et al. Symptomatic and asymptomatic left-ventricular systolic dysfunction in an urban population. Lancet 1997;350:829-33.

16. Schocken DD, Arrieta MI, Leaverton PE, et al. Prevalence and mortality rate of congestive heart failure in the United States. J Am Coll Cardiol 1992;20:301-6.

17. Ho KKL, Pinsky JL, Kannel WB, et al. The epidemiology of heart failure: the Framingham Study. J Am Coll Cardiol 1993;22 Suppl A.:6-13.

18. Mosterd A, Hoes AW, de Bruyne MC, et al. Prevalence of heart failure and left ventricular dysfunction in the general population: the Rotterdam Study. Eur Heart J 1999;20:447-55.

19. Vasan RS, Larson MG, Benjamin EJ, et al. Congestive heart failure in subjects with normal versus reduced left ventricular ejection fraction: prevalence and mortality in a population-based cohort. J Am Coll Cardiol. 1999;33(7):1948-55.

20. Değertekin M, Erol C, Ergene O, et al. [Heart failure prevalence and predictors in Turkey: HAPPY study]. Turk Kardiyol Dern Ars. 2012;40(4):298-308. doi: 10.5543/tkda.2012.65031.

21. Bonow RO, Udelson JE. Left ventricular diastolic dysfunction as a cause of congestive heart failure. Mechanisms and management. Ann Intern Med 1992;117:502-10.

22. Vasan RS, Benjamin EJ, Levy D. Prevalence, clinical features and prognosis of diastolic heart failure: an epidemiologic perspective. J Am Coll Cardiol 1995;26:1565-74.

23. Soufer R, Wohlgelernter D, Vita NA, et al. Intact systolic left ventricular function in clinical congestive heart failure. Am J Cardiol 1985;55:1032-6.

24. Aguirre FV, Pearson AC, Lewen MK, et al. Usefulness of Doppler echocardiography in the diagnosis of congestive heart failure. Am J Cardiol 1989;63:1098-102.

25. Senni M, Tribouilloy CM, Rodeheffer RJ, et al. Congestive heart failure in the community: a study of all incident cases in Olmsted County, Minnesota, in 1991. Circulation 1998;98:2282-9.

26. Redfield MM, Jacobsen SJ, Burnett JC, et al. Burden of systolic and diastolic ventricular dysfunction in the community. Appreciating the scope of the heart failure epidemic. JAMA. 2003;289:194-202.

27. Abhayaratna W, Marwick TH, Smith WT, et al. Characteristics of left ventricular diastolic dysfunction in the community: an echocardiographic survey. Heart. 2006;92:1259-64.

28. Bella JN, Palmieri V, Roman MJ, et al. Mitral ratio of peak early to late diastolic filling velocity as a predictor of mortality in middle-aged and elderly adults: the Strong Heart Study. Circulation. 2002;105:1928 -33 .

29. Fischer M, Baessler A, Hense HW, et al. Prevalence of left ventricular diastolic dysfunction in the community. Results from a Doppler echocardiographic-based survey of a population sample. Eur Heart J. 2003;24:320 -8.

30. Yamada H, Goh PP, Sun JP, et al. Prevalence of left ventricular diastolic dysfunction by Doppler echocardiography: clinical application of the Canadian consensus guidelines. J Am Soc Echocardiogr. 2002;15(10 Pt 2):1238-44.

31. Pedersen F, Raymond I, Mehlsen J, et al. Prevalence of diastolic dysfunction as a possible cause of dyspnea in the elderly. Am J Med. 2005;118(1):25-31.

32. Zhang Y, Safar ME, Iaria P, et al. Prevalence and prognosis of left ventricular diastolic dysfunction in the elderly: The PROTEGER Study. Am Heart J. 2010;160(3):471-8.

33. Mohamed AL, Yong J, Masiyati J, et al. The prevalence of diastolic dysfunction in patients with hypertension referred for echocardiographic assessment of left ventricular function. Malays J Med Sci. 2004;11(1):66-74.

34. Adamu GU, Katibi AI, Opadijo GO, et al. Prevalence of left ventricular diastolic dysfunction in newly diagnosed Nigerians with systemic hypertension: a pulsed wave Doppler echocardiographic study. Afr Health Sci. 2010;10(2):177-82.

35. Movahed MR, Ahmadi-Kashani M, Saito Y. Prevalence of suspected diastolic dysfunction in patients with a clinical diagnosis of congestive heart failure. Heart Fail Rev. 2005;10(4):263-4.

36. Chu PH, Chiang CW, Hsu LA, et al. Low prevalence of coronary arterial disease in Chinese adults with mitral stenosis. Chang Gung Med J. 2001;24(2):97-102.

37. Guray Y, Guray U, Yilmaz MB, et al. Prevalence of angiographically significant coronary artery disease in patients with rheumatic mitral stenosis. Acta Cardiol. 2004;59(3):305-9.

38. Movahed MR, Ahmadi-Kashani M, Kasravi B, et al. Increased prevalence of mitral stenosis in women. J Am Soc Echocardiogr. 2006;19(7):911-3.

39. Diao M, Kane A, Ndiaye MB, et al. Pregnancy in women with heart disease insub-Saharan Africa. Archives of Cardiovascular Disease 2011; 104:370-4.

40. Reid CL, Anton-Culver H, Yunis C, et al. Prevalence and clinical correlates of isolated mitral, isolated aortic regurgitation, and both in adults aged 21 to 35 years (from the CARDIA study) Am J Cardiol. 2007;99(6):830-4. 
41. Varadarajan P, Sharma S, Heywood JT, et al. High prevalence of clinically silent severe mitral regurgitation in patients with heart failure: role for echocardiography. J Am Soc Echocardiogr. 2006; 19(12):1458-61.

42. Singh JP, Evans JC, Levy D, et al. Prevalence and clinical determinants of mitral, tricuspid, and aortic regurgitation (the Framingham Heart Study) Am J Cardiol. 1999;83(6):897-902.

43. Panidis IP, McAllister M, Ross J, et al. Prevalence and severity of mitral regurgitation in the mitral valve prolapse syndrome: a Doppler echocardiographic study of 80 patients. J Am Coll Cardiol. 1986;7(5):975-81. 